\title{
Conforming to accreditation to Iranian hospitals
}

Dila Agrizzi

Essex Business School

dila.agrizzi@essex.ac.uk

$\&$

Gloria Agyemang

Royal Holloway, University of London

Gloria.Agyemang@rhul.ac.uk

$\&$

Ebrahim Jaafaripooyan

Tehran University

jaafaripooyan@tums.ac.ir

\section{Conforming to Accreditation in Iranian Hospitals.}

\begin{abstract}
This paper examines the operation of an accreditation programme for hospitals in Iran. It explores the process of accreditation as a regulatory control system and analyses hospitals' responses to this type of control. We draw on the notion of steering and argue that the accreditation system is transactional in nature. Our findings show that hospitals conform to the scheme, although they also resist some of its requirements. On a wider policy level, we suggest that accreditations offer the accreditor the opportunity to impact on how activities are undertaken, but hospitals require incentives in order to make the necessary organisational changes.
\end{abstract}

Keywords: healthcare, hospitals, Performance Management, accreditation, Iran. 


\section{Introduction}

Regulatory control systems exist in many forms and are broadly aimed at directing organisations towards meeting societal objectives (Broadbent et al., 2010). Whether these goals are achieved often depends on both the nature of the controls and also on how the organisations being regulated respond to the controls contained within the regulatory system. This paper focuses on one particular system of regulation, that of accreditation. Accreditation programmes are regulatory control systems aimed at assessing organisational performance against explicit standards (Shaw, 2004c; de Walcque et al., 2008; Pomey et al., 2010; Braithwaite et al., 2010; 2012). In many countries, accreditation programmes represent an endorsement of the quality of provision of a service and are often voluntarily pursued by organisations for this very purpose. For example, many UK Business Schools seek accreditation from the Association of Business Schools (AMBA and EQUIS) for this purpose (Cooper et al., 2014; Zammuto, 2008; Cret, 2011; Urgel, 2007). This paper, however, examines Iran's national accreditation programme for healthcare organizations which is the sole regulatory control mechanism used to promote quality and safety in hospitals across the country.

All accreditation systems provide certifications for compliance and for the meeting of pre-set standards (Shaw, 2004; de Walcque et al., 2008; Pomey et al., 2010; Braithwaite et al., 2010; 2012). The processes underpinning the attainment of the accreditation certificate, arguably, are regulatory control processes containing an assessment and evaluation of organisational performance against prior established standards. Previous research provides mixed messages about the nature of this control. For example, Touati and Pomey (2009) compare French and Canadian hospital accreditation systems and argue that both systems show signs of bureaucratic coercion. Hinchcliffe et al., (2012) acknowledges that accreditations are complex organizational interventions and suggest that there are contrasting messages about the extent to which professional (clinician and managerial) attitudes towards accreditation processes impact on the effectiveness of the method in promoting change. Whilst some research reveals professionals' positive views of accreditation leading to improved patient safety and care and also positively impacting on staff satisfaction, other research, for example in Egypt, suggests accreditations are considered overly expensive, bureaucratic and tend to deter organisational improvements (Al Tehewy et al., 2009). The Iranian healthcare accreditation system was introduced in 1997 with similar approaches adopted by other countries such as France and Egypt (Giraud, 2001; Touati and Pomey, 2009). It is a mandatory system intended to evaluate and rate all types of hospitals (both public and private) in terms of their performance against pre-set standards. Non-compliance to the accreditation is considered an offence that may lead to prosecution (MoH-Ministry of Health, 1997a; Farzianpour et al., 2011). However, unlike other accreditation programmes, the Iranian system includes a significant number of religious standards in addition to the clinical and organisational standards, against which hospitals' performance is compared. This provides an interesting context in which to explore the perceptions of hospital staff towards accreditation as a regulatory control mechanism, mainly because research has pointed to the re-emergence of religion in the public sphere (e.g. Beckford and Richardson, 2007; Boehle, 2010; Lewis, 2001; Kamla et al., 2006).

The aim of this paper is to gain an understanding of the perceptions of the organisational members in relation to the accreditation system, and to assess the extent to which they consider the system as transactional or relational. In order to do so, we analyse the views of clinicians and managers working in eight hospitals; six of which are publicly funded whilst two are private. We analyse their perceptions about the development and application of the accreditation standards, the periodic review process used to implement the accreditation system as well as the outcomes from the accreditation visit. Our findings show hospital participants complying with the requirements of the accreditation whilst at the same time resisting some of the requirements of the process. The main novel finding is that religion plays an important role in this context, explicating and ensuring conformity to external controls. On the other hand, resistance occurs because participants observe that the standards against which they are measured are not reflective of their organisational or national capabilities. 
The paper adopts Broadbent and Laughlin's (2013) notions of "steering"1 to theorise the findings, arguing that accreditation programmes are examples of "societal steering mechanisms" that seek to regulate and control the activities of organisations (Broadbent and Laughlin, 2013, page 66). These steering mechanisms may be transactional, supported by the force of law or funding, or may be negotiated and relational. Societal steering mechanisms, as explained later, create environmental disturbances for organisations that may lead to four possible responses: rebuttal, reorientation, colonisation or evolution (Broadbent and Laughlin, 2013; Laughlin, 1991). This theoretical framing enables an analysis of the nature of accreditation as a form of regulation, as well as an analysis of the responses the organisations make to them. Our central argument is that in Iran hospitals conform to accreditation because of the force of the law, the funding ramifications associated with the regulation and also because of shared religious values. Despite this, there is a latent resistance because the desired organisational standards contained in the accreditation steers are perceived as unrealistic and unattainable and out of synch with organisational values.

Our paper contributes to the control literature in two ways - conceptually and empirically. Conceptually because, while previous literature have suggested that transactional steering may achieve its societal goals due to the force of law and funding, we argue that strong shared values (in this case Islamic values) may also lead to conformity to transactional steering. Whilst there may be resistance to transactional steering systems, such resistance may be mediated by shared religious values. These have a moderating effect on the way societal steering control mechanisms such as accreditation are perceived by organisational members. At an empirical level, we contribute to the understanding of reorientation strategies in a developing country and within an Islamic context. Whilst Broadbent and Laughlin (2013) explain reorientation through absorption and boundary management, we introduce reorientation through both conformity and resistance, without any specific organisational processes changing. These contributions are important for two reasons - the dearth of research considering the perception of participants to the control elements contained in accreditation programmes, despite the fact that accreditation is the longest-established and most widely-known method of evaluation of healthcare services in the world (e.g. WHO-World Health Organisation), 2003; Shaw, 2004b; Shaw, 2004c; Scrivens and Lodge, 1997 \& many others) and given the scarcity of research related to accreditation programmes in developing countries (Hopper et al., 2008; Hoque, 2014).

The paper consists of six sections. The next part discusses accreditation systems generally and also specifically in terms of healthcare. An argument is made as to why they can be considered regulatory control systems. In section three we explain the main elements of Broadbent and Laughlin's (2013) theoretical framework, whilst in section four we discuss our research methods, including a contextual introduction to the Iranian healthcare accreditation system. Section five provides our empirical findings and our analysis of organisational responses to this mechanism. We conclude the paper by discussing the findings and addressing the implications for policy and further research in section six.

\section{Accreditations and Regulatory Control Systems}

\subsection{The nature of accreditation systems}

In broad terms, accreditations are external assessments of a service provision. They intend to provide an external endorsement to the organisation, thus its services and outcomes can meet prescribed thresholds. In the education sector, for example, accreditations are external quality reviews used to scrutinize institutions and education programmes with the goal of improving the quality of provision (Cooper et al., 2014; Eaton, 2006; Stensaker and Harvey, 2006; Invargson et al., 2006). The first attempts to use

\footnotetext{
${ }^{1}$ The work of Broadbent and Laughlin with respect to steering was presented in several academic articles, and they collated all their work in a single text in 2013 - i.e. Broadbent and Laughlin (2013).
} 
accreditation date back to 1910 in the United States (McIntyre et al., 2001) and soon it was replicated in other English-speaking countries, such as Canada (in 1958), Australia (1974), and then in Europe (Shaw and Brooks, 1991; Giraud, 2001), Latin America (Arce, 1999), Africa (Whittaker et al., 1998) and South East Asia (Ito et al., 1998; Huang et al., 2000). A significant amount of accreditation takes place in the healthcare sector. De Walcque et al. (2008) suggests that healthcare accreditations are "initiatives [that] externally assess hospitals against pre-defined explicit published standards in order to encourage continuous improvement of the health care quality" (de Walcque et al., 2008, p. i). Where the hospital achieves the threshold and compliance is achieved, it receives a certificate of accreditation, which is valid for a specific period of time (Scrivens, 1995a).

Having a certificate of accreditation arguably conveys several benefits for an organisation and the extent to which these benefits actually accrue has been widely researched (see for example Montagu, 2003; Pomey et al., 2004; Pomey et al., 2010). The benefits can be categorised into those associated with the processes of providing and improving healthcare, those associated with the management of healthcare organisations, and those associated with external stakeholder perceptions about healthcare. In the first category, accreditations may provide the organisation with a validation of excellence and may stimulate a focus on improving the quality of care within hospitals. Arguably, this focus on continuous improvement is the key goal of accreditation processes. The second group of benefits relates to impacts on people working within the organisations. For example, accreditations may provide recognition of the skills of personnel; it may motivate workers and may encourage staff education as they become more aware of best practices (Duckett, 1983; Cerqueira, 2006). The third category of benefits includes facilitating community confidence and improving the reputation of the service provider amongst its end users (Montagu, 2003; Pomey et al., 2010). Contained within this last category are suggestions that accreditation also enables the organisation to demonstrate public accountability and accountability to funders (Halverson, Nicola and Baker, 1998; Cerqueira, 2006).

A generic accreditation process is depicted in Figure 1 below.

Accreditations depend on the use of pre-determined standards of performance to measure and assess organisational activities against those standards (as shown in Figure 1 below). The choice of standards, their focus, and the level at which they are set are paramount in determining the tone, acceptability and nature of the system. Accreditation programmes may be focused on standards set for structures, processes or health outcomes (Zende, 2006). The structure approach prioritises the structural facilities that are available to the hospital such as equipment, human resources, physical and space specifications and layout (i.e. hardware) in hospitals (Haigh and De Graaf, 2009). Standards are, therefore, established for these resources. Where processes are used as the standards, the accreditation programme focuses on quality assurance activities and the standards concentrate on the process of care, rather than on the physical structures. Alternatively, the focus of the accreditation programmes can be on the health outcomes, relying on customer's charters to assess the extent to which the healthcare system is accessible and acceptable to patients.

Fig. 1. Generic accreditation model

Source: Adapted from Braithwaite et al., 2011, page 2.

The use of standards is aimed at facilitating the systematic reviewing of complex systems. The credibility and the effectiveness of accreditation programmes to a large extent depend on the reliability of the standards that are chosen to assess the activities. This is because they should facilitate the assessment of the current situation and consequently should help to identify the improvements needed to deliver healthcare services. Whether they actually do, is debatable and a number of studies have indicated the problematic nature of achieving these goals (Scrivens, 1997a; de Walcque et al., 2008). The standards are applied against current organisational activities typically by way of self-assessment (such as filling out questionnaires), desk appraisal of internal documents and on-site visits, usually by peers (Montagu, 2003; Braithwaite et al., 2011). 
Although all accreditations involve external assessment or an assessment by some independent authority they need not be obligatory, nor are they necessarily government requirements. The accrediting authorities may be public or governmental departments, or their agencies as in the case of healthcare accreditation in France and Italy (Montagu, 2003; Pomey et al., 2004; Pomey et al., 2010). But they can also be undertaken by private organisations that do not have affiliation to government. Eaton (2006) identifies four different types of accrediting bodies in the US education system. These include regional or state accreditors; national accreditors; faith based accreditors as well as career or professional accreditors. In Europe, Stensaker and Harvey (2006) similarly identify both the existence of private and public accrediting bodies. For example, the General Medical Council in the UK is a public accrediting body for medical education. Where the accrediting body is a public organisation, the accreditation is often compulsory and necessary for operating or providing the service.

This broad description has shown that accreditations take various forms and that the benefits associated with them are by no means certain. Our focus in this paper is on accreditations as an example of a regulatory control system and it is to this we now turn.

\subsection{Accreditation as a Regulatory Control System}

Regulatory controls are external controls, which may trigger internal organisational changes (Broadbent and Laughlin, 2013). They may take a variety of forms, including legislation to specify requirements, use of funding and inspections. Accreditation systems can be considered examples of regulatory control systems for several reasons. Firstly, in order to obtain the accreditation, organisations are assessed against externally designed standards. The standards are intended to cover all aspects of healthcare provision by investigating the organisation in terms of management and clinical performance (Braithwaite et al., 2011; Greenfield and Braithwaite, 2008; Pomey et al., 2010; Shaw, 2004b). Many of these standards are often defined in the language of control; for example as output standards, input standards and process standards that are used to measure the performance of the organisation (Montagu, 2003; Neely et al., 2001; Brown, 1996). In healthcare accreditation, the output standards reflect the outputs expected from the service such as number of patients treated, incidence of infection, accuracy of clinical diagnosis, patient satisfaction and may include both quantitative and qualitative measures. Input standards concentrate on resources and facilities used to provide the service. Process standards consider how well activities are undertaken and increasingly require continuous improvement in the quality of care. Management processes and clinical processes are examined for their effectiveness. With this focus on standards and the evaluation of hospital performance across the spectrum of hospital activity, accreditations are, in essence, regulatory control systems. The standards act as targets and may represent formal controls, "deliberately articulated" for control purposes with the inherent objective of fostering change (Chenhall et al., 2010, page 742). Through the examination of achievement of performance against standards, accreditation programmes are depending on performance measurement systems, as part of management control systems, to exert organisational changes (Zende, 2006; Gifford and Garcieri, 2007; Broadbent and Laughlin, 2013; Agyemang and Broadbent, forthcoming). Where organisations are not successful - i.e. they do not meet the requisite standard after an accreditation

process, they often are subject to further accreditation visits and reviews. Even where organisations are successful and receive the accreditation certificate, they often are still subject to further visits and reviews in subsequent years to ensure that standards are maintained and improved.

Accreditation systems operate in similar ways to the public management performance measurement systems used in many countries in the 1990s as part of the mechanisms of New Public Management (Hood, 1991; 1995) to evaluate the performance of public sector organisations. Key similarities include the evaluation of organisational performance against a set of criteria, and the systematic appraisal and collection of information, frequently undertaken by external bodies. The main difference between 
accreditation and these other systems, however, relate to the purpose of the evaluation. Hood (2007) ${ }^{2}$ suggests that there are three purposes to public sector management by numbers. They may be used as targets, with the standards being aspirational. On the other hand, the purpose of collecting the metrics may be to rank performance of different organisations in order to inform user choice and to inform government action, "or simply as a means for encouraging 'saints' and shaming 'sinners' (Hood, 2007, page 95). Essentially this is ranking for accountability purposes. Performance measures may also be collected just for background intelligence information gathering. Annual performance metrics systems, such as the UK National Health Service (NHS) trusts star ratings system employed by the UK government (which have been published in England since 2001), demonstrate both target setting and ranking purposes (Agrizzi, 2008). Where the performance measurement system aims at ranking, the external controls and organisational change may be more direct as organisations attempt to avoid the "naming and shaming" subsumed in the ranking. The star rating system sought to give the public performance information about their local hospitals, but had direct consequences for hospitals when found to be "failing" (Agrizzi, 2008). For example, hospitals achieving zero stars were required to provide action plans to demonstrate how performance would be improved and, in other instances, senior managers were held accountable for low performance and lost their employment (Agrizzi, 2008; Bevan and Hood, 2006; Chang, 2007; Mannion et al., 2005). Accreditation systems may be motivated by the first purpose where the pre-set standards are aspirational targets of performance. On the other hand, they differ from other systems because they emphasise compliance to the standards in order to award certification for this compliance, rather than "naming and shaming". Thus their inherent external control may be more hidden and less obvious.

Literature has shown the potential tension between the use of external measures of performance and internal organisational beliefs of what should be measured (Broadbent and Laughlin, 2013; Bevan and Hood, 2006b). In hospitals for example, the perspective held by some physicians, nurses and scientists, is that externally-defined performance measurements are simply unpractical to use (Loeb, 2004). There is the argument that medical professionals tend to believe that, what gets measured in healthcare organisations is frequently the easiest and cheapest aspects of care, which are commonly of least importance in improving quality (Loeb, 2004) and that the intangible and long-lasting outcomes are ignored, due to the difficulty of measuring them (De Bruijn, 2002; Fried, 2010). Furthermore, there is the problem that patients with seemingly similar conditions may respond in different ways to similar clinical treatment. External pressures through accreditation, as with other external controls, may impact on the behaviour of hospital management and medical staff in unintended, perverse, and dysfunctional ways (Agrizzi, 2008; Lehtonen, 2007; Conrad and Uslu, 2012; Abernethy and Chua, 1996; Abernethy et al., 2007; Kurunmaki, 2004; Modell, 2001).

Pomey et al. (2004; 2010) have looked at some elements of this by considering whether and how accreditations lead to organisational change in hospitals in France. They argue that the mandatory nature of the system created strong pressure for change within hospitals, and that it was in the preparation for the accreditation visit that some changes could be seen. Hospitals tend to react in bureaucratic ways; holding meetings to prepare the standards manual. Despite this, there was evidence of a more a consensual and participatory sharing of information and communication between all levels of the organisation. Additionally, the process, "translated primarily into the development of values shared by the professionals of the hospital and the creation of an organizational environment which is more conducive to fostering better treatment of patients" (Pomey et al., 2004, page 122). Finally, they suggest that the preparation for accreditation led to the introduction and use of performance indicators in the

\footnotetext{
2 These are "pure" types but over time many systems have developed hybrid forms combining elements of targets, rankings and intelligence.
} 
management of activities. Clearly, there was evidence of some acceptance and at least some reorientation in the management control systems to handle the pressures introduced by the accreditation system.

\section{Regulatory Control Processes: steering types and organisational responses}

As argued above, accreditations can be considered examples of regulatory control systems used to direct internal organisational systems. The work of Broadbent and Laughlin (2013) provides a conceptual lens by which the relationships between these controls and organisational responses can be examined. They provide a "middle-range thinking" research approach that dwells upon the use of a skeletal theoretical framework for studying regulatory control processes (Laughlin, 1995; 2004). Theoretically, Broadbent and Laughlin argue that institutions are developed at societal levels to regulate other organisational systems. These institutions are government departments that employ financial resources and the administrative power of law to direct organisational behaviour. Their role is to act as "societal steering media" whilst the organisations they steer have functional responsibilities. Thus, in the case of healthcare, a Ministry of Health would be an example of a societal steering medium, while the hospitals are the organisations being directed to provide healthcare. Various steering mechanisms (such as funding, the law, and we argue, accreditations) may be employed by societal steering media to steer organisational activities.

\subsection{Types of steering mechanisms used in regulatory controls}

Broadbent and Laughlin identify two ideal types of steering mechanisms and discuss their nature in terms of the underlying rationalities used in their development. Where an instrumental rationality underpins the design, transactional steering mechanisms may be developed. Steering processes that take the transactional approach define the outputs and outcomes desired (the ends), and may also specify the means to be used to achieve these ends. The approach may be illustrated by the regulatory relationship that exists in the context of a contract to undertake a particular project over a definable period of time (Broadbent et al., 2010, page 508). The objectives of the contract are defined; the process is defined as well as the rewards (for achieving the objectives) which are usually financial. Transactional approaches have instrumental goals and tend to be "command and control" approaches with the key purpose of achieving specified ends operating as a "something for something" and without negotiation between stakeholders. Alternatively, where a communicative rationality underpins the development of the processes, more relational steering approaches are used based on negotiation and communication, and are, therefore, less prescriptive. Thus, the goals of relational steering would have been agreed through deliberation and discourse between stakeholders, whilst with transactional steering the purposes are achieved through formal (and usually financial) exchanges. Relational steering is regulative in the sense that it is guarantees freedoms, regulating established behaviours and so may be seen as justifiable as compared to transactional steering which reduces the freedom by which organisations may act (Laughlin, and Broadbent, 1993, page 341; Laughlin, 2007). Transactional and relational steering processes exist on a continuum that represents "ideal types" mechanisms. Table 1 summarises the differences between transactional steering and relational steering.

Table 1. Types of steering processes

Source: adapted from Broadbent and Laughlin (2009)

\subsection{Organisational responses}

Broadbent and Laughlin's notions of steering enable an unpacking of the complexities of regulatory controls and organisational responses because they consider both the tangible structures (such as, organisations, laws, and funding regulations, management systems) as well as intangible elements (such as shared values) which may help in explaining how people respond. The intangible elements are especially important because they are the interpretive schemes that "operate as shared fundamental assumptions about why events happen and how people are to act in different situations" (Bartunek, 1984, page 355). In Islamic countries such as Iran, "every act of believers must conform to Islamic Law" 
(Lewis, 2001, page 104) and therefore these religious values are important interpretive schemes that would influence the response organisations make to regulatory controls. They would also supposedly be the taken for granted values that are incorporated within the content of the regulatory controls deriving from the Iranian government. However, there are different levels of abstraction with respect to interpretive schemes that can also impact on the responses to regulatory controls. They can range from core processes (communication and decision processes), culture (beliefs, values and norms) to mission (purposes and programmes of activities) (Laughlin, 1991, page 213). Therefore, it is possible for organisation participants to share the same beliefs and cultural norms (such as religious values) with the regulatory controllers and yet hold different organisational values (in terms of view and beliefs about mission and purpose) from those being controlled. For example, there may be different "measures of quality, relevance or excellence" flowing from the societal steering media to the organisations and it is possible that those working within organisations may not understand "the imperatives behind them" (Broadbent et al., 2010, page 507). This could then impact on how the organisational members respond to attempts by the societal steering media to improve quality. There may be contradictions in the organisational responses to the regulatory controls, with some controls being considered acceptable and others seen as non-acceptable and, therefore, needing to be resisted. The complexities of organisational responses stem from the possibility of differing value systems being held by the organisations (e.g. hospitals) and societal steering media (e.g. Ministry of Health).

Laughlin (1991) discusses four possible organisational responses to regulation: rebuttal, reorientation, colonisation and evolution. Rebuttal is the situation where organisational members find ways to deflect (and thereby reject) the controls emanating from regulation on the basis that as organisational members they know how the organisation functions. Often it is not possible for organisations to rebut external regulation especially where the regulation is backed by law and where it is transactional. In the reorientation response, the organisational members accept that the external regulations cannot be rebutted and they make some organisational changes to processes and functions whilst keeping their interpretive schemes (core beliefs, and organisational value systems) intact. Reorientation is a form of resistance, though less manifest than rebuttal. Broadbent and Laughlin (2013) argue that reorientation is the most common response to external regulations. Furthermore they identify two ways by which reorientation may happen: either by absorption or by boundary management. In the absorption situation, a specialist group is created within the organisation to cope with and "soak up" i.e. handle the disturbances whilst the main organisational activity continues (Broadbent and Laughlin, 2013, page 214). With the boundary management form of reorientation, a select group of senior managers lead changes in the daily activities of the organisation, whilst protecting the organisational interpretive schemes (Broadbent and Laughlin, 2013, page 227). Rebuttal and reorientation are first order changes that do not involve the interpretive schemes changing. The other two change pathways, colonisation and evolution, both involve the underlying organisational interpretive schemes changing either through coercion (colonisation) or by agreement (evolution). Laughlin (1991) offers these pathways as skeletal conceptual frames in terms of middle range thinking, which can only be substantiated through empirical analysis.

Our argument is that accreditation programmes are examples of regulatory control systems (i.e. steering mechanisms) that aim to steer hospital organisational activities through the accreditation standards. The standards need to provide real world guidance and should be reflective of situations faced by healthcare organisations, if they are to act as a catalyst for change (Duckett, 1983; Halverson et al., 1998). This suggests that there is a need for standards to be negotiated. Relational processes may facilitate the setting of appropriate standards which may satisfy the requirements of all stakeholders. Whether the processes associated with accreditations are transactional or relational requires empirical investigation.

The Broadbent and Laughlin notions of transactional and relational steering provide a language for interrogating empirical findings about the nature of the standards, and the processes used in accreditation programmes. The term, rebuttal, reorientation, colonisation and evolution provide ways of analysing the responses of the participants to the programme. Previous studies that have analysed organisational 
responses to institutional processes in healthcare organisations mainly using New Institutional Theory (e.g. Modell, 2001; Abernethy and Chua, 1996) and have found legitimacy seeking rationales to be key in explaining organisational responses. We draw on Broadbent and Laughlin's ideas to render an institutional analysis that is "more sensitive to the wider, social implications" of accounting practices (Modell, 2015). Broadbent and Laughlin's theoretical concepts enable a fuller analysis of the complex nature of regulation, whether they are transactional or relational, as well as a more nuanced analysis of the responses that organisations make to them. Such responses may be more complex than the desire for legitimation. Organisations may reorient themselves to the accreditation steer, but such reorientation may occur in different ways and for different reasons. As previous literature has shown resistance to regulatory controls happens when the organisational value systems are different and where the organisational changes contained in transactional steers are perceived as unrealistic and unattainable (Broadbent, Laughlin \& Jacobs 2001). Reorientation, though a way of resisting the external control, may occur alongside conforming to the controls. Transactional steering leads to conformity because the controls are legally enforceable. Additionally, there may be conformity to transactional steers because of shared religious beliefs held by both the regulatory steering media and the organisational systems.

\section{Research methodology and methods}

\subsection{Research methodology}

This study forms part of a major study that examines the performance management systems employed in Iranian hospitals. It adopts a mini case-study design using a purposive sampling technique for choosing the hospitals under inspection of the national accreditation program for hospitals in Iran (Kerssens-van Drongelen, 2001; Yin, 2008; Ritchie and Lewis, 2003). All the hospitals were intentionally selected to reflect their participation in the accreditation program and they are all located in the same province and, therefore, subject to the same accreditation regime. The paper draws its empirical findings from mini-case studies from eight hospitals. Six out of the eight are publicly funded, whilst two are private (Table 2). Multiple mini-case studies allow an exploration of real-life phenomena although a limited amount of data may be collected from each case study (Kerssens-van Drongelen, 2001). They enable the development of tentative explanations especially when the cases are based on theoretical replication (Kerssens-van Drongelen, 2001; Van Aken, 2005). It was thus possible to gain a broad view of organisational responses to the system (Van Aken, 2005). The aim is to gain an understanding of the perceptions of the organisational members in relation to the accreditation system, and to assess the extent to which they consider the system as transactional or relational.

\subsection{Research methods}

A purposive sampling technique was also applied for selecting the respondents. The main criterion was familiarity with and involvement in the accreditation and evaluation processes of the accreditation programme within the hospitals. Therefore, participants were selected according to their ability to provide appropriate data (Mack et al., 2005). We conducted face-to-face semi-structured interviews (Pope and Mays, 2006) with clinicians and managers including fifty-nine participants working in the eight hospitals and nine accreditation surveyors. The total of sixty-eight interviews took place between 2009 and 2011. One of the authors went to Iran on several occasions to conduct the interviews, as he is fluent in Farsi. The Ministry of Health was mostly cautious about giving access to the sites. A range of documents (including letters from our university confirming the researchers' affiliation) were required by the Bursary Committee, part of the Iranian Ministry of Health. Access to the hospitals was granted only after several months. A further long and bureaucratic process was followed inside each hospital before initiating the data collection. We reassured the management team and the participants of the purpose of the research and informed them about the research ethics of our institutions. A consent form indicating to them that their participation was voluntary and that they could withdraw at any time were distributed to them. A Participant Information Sheet form explaining the purpose of this study was also given to them. Despite their busy schedule, they all accepted to participate in the research and the 
interviews were finally pre booked. The interviewees were very cautious about providing inside information. Thus, further and continuous reassurance in terms of confidentiality and anonymity was again necessary before the interviews started. Nonetheless, they were very cooperative, mainly because, they indicated, they would like to see some change in the accreditation process. Attendance at meetings was not allowed.

Analysis and review of the Ministry of Health's official documents and an informal evaluation showed that the senior, middle and junior administrative and clinical managers from different hierarchical levels of each hospital were the most knowledgeable and deeply involved in accreditation process of the hospitals (see table 2). We also interviewed the accreditation surveyors (as outsiders; those who play the role of external controller), in order to corroborate information provided by the hospitals' participants and minimise the potential for bias, - i.e. in an effort to increase the validity of the data and cross-checked them with relevant documents (Mellahi and Wilkinson, 2004).

Table 2. The number of interviews conducted in the hospitals.

\subsection{Analysis of documentation and observation}

To develop further understanding of the process of the accreditation system in Iran, several documents were reviewed and analysed, including two groups - internal (related to hospitals) and external (issued by Ministry of Health) documents. This process was supplemented by interviews held with the accreditation surveyors. Both these interviews and the analysis of documentation were significant sources of information, enabling us to gain a fuller understanding of the context of the systems as well as the issues underpinning their rationalities - i.e. whether transactional or relational.

One of the researchers was granted permission to participate in one accreditation program of one of the hospitals. This observation allowed perception of the way the system takes place in practice and the interactions between surveyors and hospitals' staff. This provided further understanding of the participants' actions and substantiated the data collected from the hospitals' personnel in the absence of the surveyors.

All the other sources were then translated and cross referenced and checked against other available primary data. Data was analysed both intuitively and through the use of computer-assisted qualitative data analysis software (NVivo-version 8 - CAQDAS). We employed the conceptual frame to help identify quotes and phrases from the interviews relating to participant perceptions about accreditation standards whether transactional or relational. We also considered the extent to which the responses of the interviewees signalled whether they were conforming to the accreditation steer or whether they seemed to be resisting the steer. One of the strengths of the middle-range thinking research approach is that it enables the drawing on "a rich source of primary data, with the benefits of an informed" skeletal approach to derive meaning and understanding of the empirical situation (Richardson et al, 1996, page 10). Thus our theoretical model provided us with a language to enable us to interpret our findings.

\section{The Iranian National Accreditation Programme: a Regulatory Control System}

\subsection{The Iranian Healthcare System Context}

Iran is a member-state of the Eastern Mediterranean Regional Office (EMRO) ${ }^{3}$ of the WHO and the healthcare system has been restructured and steadily improved during the past three decades (Mohit, 2000). The Ministry of Health is the ultimate authority of the country's healthcare - i.e. responsible for the aspects of planning, policy-making, leading, supervising, funding and evaluating the healthcare

\footnotetext{
${ }^{3}$ EMRO includes countries from the Middle East and the northeast of Africa, such as Yemen, Lebanon and Morocco.
} 
services and medical education (Mohit, 2000). In one document the Ministry of Health explains its responsibilities as (MoH-Ministry of Health 1997a):

“...to define the principles of assessing, monitoring and controlling of healthcare institutions and to implement them."

The Ministry of Health specifies standards for healthcare services and is also responsible for financing health from public sources. Arguably, therefore, the role of the Ministry of Health is to steer in a transactional manner as it is responsible for financing, planning and assessment of performance of the healthcare centrally.

At the provincial level executive responsibility has been given to the Universities of Medical Sciences and Health Services (the UMSs). The task of providing healthcare services and training the required human resources at all levels of education also concerns the UMSs (Bahadori et al, 2015; Farzianpour, et al., 2011; Majlis, 1985; 1987; 1988a). The chancellors of the universities, who are also the deputies of the health minister in their respective province, are the executive directors of the provincial care services and in charge of all hospitals and healthcare centres. Provision of healthcare services in Iran is undertaken at three levels; primary, secondary and tertiary. Primary care is mostly provided in rural areas by some basic health centres whereas secondary care includes the more advanced services and initial access to district hospitals. The tertiary care includes the UMSs and hospitals, which provide the most advanced healthcare services. Hospitals are conventionally recognised as organisations with a clinical orientation, with their main focus on the provision of care (Jacobs, 2001). The hospitals examined here were not seen as exceptions to this rule. Staff indicated that 'serving the society as a hospital' is the raison d'être of their organisation. The review of policy documents of the hospitals (e.g. strategic plans) and the interviews showed that the core of their mission is to deliver high quality and safe services to the satisfaction of their internal and external stakeholders.

As explained earlier, the Iranian healthcare system comprises of both public and private care provision. The public hospitals are partly funded by the state through a central budget scheme. Private hospitals can either be for-profit and not-for-profit (charity) categories. The public hospitals are subdivided into university and institutional hospitals. These are also divided into two groups: teaching hospitals (which provide clinical services and undertake medical training, education and research) and the clinical hospitals (which are responsible only for delivering clinical services). The former, unlike the latter, are mostly located in the big cities of the provinces. The university hospitals are governed and operated by the University of Medical Sciences. The University of Medical Sciences is also responsible for operationalising and implementing the accreditation and evaluation of hospitals within each province.

Part of the hospitals' revenue for both the private and public hospitals is determined by their income from the clinical services they provide. Clinical services are priced based on the accreditation grade of the hospitals signalling the importance of achieving a good grade from accreditation process (see table 5), and arguably suggesting that the accreditation scheme is set up as transactional or as "something for something logic" (Broadbent and Laughlin, 2013, page 261). Where hospitals meet the regulatory requirements set by the Ministry of Health, they are allowed to charge the highest rate for their clinical services. The accreditation rating status of private hospitals is used as a threshold for their eligibility to raise their tariffs for "hotel-type" services, (MoH-Ministry of Health 1997a), which are the main source of the private hospitals' income. Within the private hospitals patients are usually treated in private rooms which have hotel-type facilities such as TV and menu choices. They are also referred to as customers. The higher the grade the private hospitals receive in their accreditation, the higher the tariffs they can charge for their hotel-type services, thus further increasing their income. Insurance organisations also reimburse the private hospitals according to their accreditation grade. This income for non - clinical hotel type services is a key stream of revenue for private hospitals. 
In the analysis which follows next, we explain the nature of the accreditation processes and the effects it has on the organisational responses.

\subsection{Transactional development of standards}

The first attempt to introduce an accreditation system in Iran took place between 1962 and 1967. It started simply as a set of checklists and was developed on the basis of a USA accreditation system which was considered by Iranian authorities to be a successful scheme adopted internationally (Sadaghiani, 1997; Shaw, 2004c). In 1994, the Joint Commission of International (JCI) introduced international accreditation health standards. These standards were considered the "best in the world" for quality healthcare and patient safety and became the basis for development of the Iranian national accreditation standards (Bahadori et al, 2015; Farzianpour et al., 2011).

There are several steering organisations that operate together to accredit the hospitals. The Centre for Healthcare Accreditation and Supervision is a division created by the Minister of Health for undertaking policy-making, planning and direction of hospital accreditation and evaluation activities. There is a subdivision within this centre known as the Healthcare Organisations Evaluation Group which deals directly with planning and policy-making activities.

The standards within the accreditation programme are established at macro level in the Ministry of Health and officially dispatched to the various UMS at micro level to be used for the accreditation of the hospitals. The existing documentation on the initiation of the national accreditation programmes shows that, in 1997, the formal guidelines for the accreditation were developed under the Treatment and Medication Undersecretary of the Government, and then placed to the convention of the Chancellors of the UMS and their Deputies for Treatment, and then finally sent to the hospitals to be observed in their practices (Moghimi, 2004; Sadaghiani and Zare, 2005). This approach to developing the accreditation system suggests that from the outset the purpose of the accreditation was one of control with the Ministry of Health taking the lead. Control is often a key purpose of transactional steering mechanisms (Broadbent and Laughlin, 2013, page 81). This perception was constantly suggested by interviewees, as they argued that they could not affect the accreditation standards formally or informally as their feedback was not sought nor incorporated to introduce any changes. For example:

"No feedback is asked from this hospital to improve the accreditation programme. We reflect on the problems though! But nothing has changed based on our views so far. What we say is mostly in an informal way and to the surveyors, because there is no formal process in place asking our feedback." (Head of A\&E: Hospital H. a public hospital)

There are currently sixteen general domains of activity covered by the standards of the national accreditation programs for hospitals (Table 3). Each domain poses a number of questions and statements in the form of checklists in an attempt to cover all aspects of hospital activity (MoH- Ministry of Health, 1997a).

The set of accreditation standards listed in Table 3 indicates a considerable emphasis on the hospitals' physical and structural aspects, input focus rather than processes and outcomes standards (e.g. standards 6- establishment and physical structures; 7- Safety equipment; 8- Non-medical equipment; 9- Medical equipment; and 11- Information system and medical records). These represent 28.9 per cent of the total score. Standards 2, 3, 4, 5 and 13 relate to the administrative aspects of the hospitals, representing 41.4 
per cent of the total score. Few standards are associated with output standards. For instance, Standard 10 (patient satisfaction), which makes only 4.7 per cent of the total proportion ${ }^{4}$.

It seems, therefore, that the focus of regulatory control was on the physical resources to ensure that the hospitals were equipped to offer services. This focus on structures and input resources was something interviewees commented on and something they seemed not to agree with. For example:

"Checklists are mostly concerned with physical and structural matters and not with hospitals' processes, whilst both should be covered by the accreditation programme." (Matrons: Public Hospital F)

A key objective of the Ministry of Health is to "provide facilities for public enjoyment of healthcare by establishing and expanding public health centres and improving their standard" (Malji, 1988, p.1) and therefore, from the perspective of the regulators, it is important to ensure this happened. As the documentary analysis of the evaluation checklists showed, surveyors tend to spend a significant amount of time checking the physical capacity of the hospitals to provide care. It has also been acknowledged by the authorities that the main focus of the accreditation programme is on the physical structures of the hospitals (Moghimi, 2004). The hospitals, as the above quote shows, seem to suggest that there should be an emphasis on processes rather than inputs. Here we see that some aspects of the hospitals' organisational values differ from the contents of the accreditation standards. Whilst both the regulators and the hospitals are interested in the health of the Iranian people, the mission or intentions of the regulators were projected as being too focused on physical resources.

In some cases, hospital departments exchange equipment to influence the accreditation scores whilst in other instances they claim to make unnecessary purchases.

"...they [the accreditation surveyors] require expensive and unnecessary equipment that we cannot buy, so we may borrow them from other departments only for the period of the survey." (Head of Laboratory: Private Hospital H)

"We are asked to buy some material or equipment that we don't use too often and as a result of which the hospital incurs costs. But since it is a rule we must obey- e.g. buying a LP set, which is rarely used in this ward." (Matron: Public Hospital F)

"We get prepared for the evaluation [by the NAPH] - sometimes superficially. We put some medical equipment such as "infusion pump or incubator" in our A\&E which we do not use, and we believe they are not necessary... ....we take them away and return them to its previous ward after the evaluation." (Head of A\&E: Hospital B-Public)

"We must prove the average time, after which a physician visits or nursing services are delivered to a patient arriving at the $\mathrm{A} \& \mathrm{E}$, has reduced during a period of six months to get the related evaluation score. In practice, to be honest, this might not always happen in this department because of our shortage of staff. In busy times we bring staff from other departments to keep the waiting times down, but this is not possible in the long term... although their score is very low, they must be met, according to the regulations." (Head of A\&E: Hospital E-Private)

\footnotetext{
${ }^{4}$ There are several studies finding no relationships between accreditation and patient satisfaction (e.g. Greco et al., 2001; Heuer, 2004). Similarly, patient-reported measures of quality and satisfaction of both accredited and non-accredited health plans could not be differentiated (Beaulieu and Epstein, 2002).
} 
All these statements suggest attempts to comply with hospitals seeing the requirement as "a rule to be obeyed". In effect the accreditation system is seen as one of "command and control". But by borrowing equipment, the hospital is also resisting the steer to own equipment that they consider unnecessary. Therefore, it seems that the hospital staff are, at the same time, seeking to both conform and resist to the controls. There is some amount of gaming taking place to allow them to demonstrate compliance.

Most interviewees indicated that they perceive the accreditation programme to be a top-down oversight system. The accreditation's sole purpose, to them, is to remind staff of a need to meet a target number they considered to be meaningless and to engage in a seemingly meaningless and routinised process.

"Evaluation activities have been routinised ... - they are repetitive every year." (Head of ED: Hospital B)

“...seeing similar evaluation process every year with the same checklists, honestly, I don't bother to think of that seriously... When preparing for the evaluation, we sometimes do not try to go and check the checklists of the accreditation ... we have memorised all what they may want and, therefore, we just change what is important for the evaluation." (Matron: Hospital B)

These quotes suggest that the steering inherent in the accreditation is seen by hospitals as transactional, and underpinned by instrumental rationality. That is to say, the standards are not established in a relational manner, through dialogue and seemingly do not seek the agreement of stakeholders, but rather compliance (Broadbent and Laughlin, 2009; 2013).

Table 3. Accreditation standards and corresponding scores for hospitals' activities.

Source: Adapted from Moghimi (2004, p. 26)

In 2004, attempts were made to make amendments to the 1997 standards and to introduce new qualitative standards (MoH-Ministry of Health, 2004). Such attempts were to make the programme more 'qualityoriented' (Moghimi, 2004). The idea was to update the standards gradually by adding more qualityoriented standards. The aim was to encourage a focus on the quality of the service delivery in the hospitals (MoH-Ministry of Health, 2004). The Ministry of Health launched a supplementary programme called the 'Practical instruction for the quality evaluation of hospitals' as a pilot scheme from 2003, and in a compulsory fashion from 2004 (MoH-Ministry of Health, 2004). These guidelines were expected to accomplish three important goals as follows:

"To assist with improving quality in hospitals; to provide necessary information for decisionmakers (possibility of informed decision-making); to enhance the level of accountability and regulation of HCOs." (MoH-Ministry of Health, 2004, p. 2)

These new standards specified what the government is looking for from hospitals, seemingly moving away from inputs to processes and outcomes and towards improving the quality of provision. They reasserted the government's desire to ensure the hospitals' ability to deliver quality and safe care and 'continuous quality improvement' at all levels of the 'general hospitals' activities (Moghimi, 2004, p. 5). Table 4 provides the quality-oriented standards developed as a result of the Government's policy introduced in 2004. They are, therefore, part of the current hospitals' accreditation (item 15 of Table 3). Although these indicators reflect a progress towards measuring quality in the hospitals, they only represent 2.9 per cent of the overall score of the accreditation for hospitals.

Table 4. Quality-oriented indicators of the accreditation programme

Source: adapted from MoH-Ministry of Health, 2004

The reaction of the hospitals was no different to these quality standards; they felt they had to comply with the standards though they did not agree with them. For example: 
"In the case of nosocomial infection, they insist that we find more cases of patients with this condition and, if we report fewer cases, they will assume that our case-finding system is not working properly, while we think fewer cases should be better." (Manager: Public Hospital C)

Thus, what seems to be happening through the accreditation is the implementation of an ex ante accounting information system to monitor and control the hospitals irrespective of the views of managers and clinicians and irrespective of the interpretive schemes held by organisational members (Broadbent and Laughlin, 2013, page 78). Transactional ex ante information reflect exchange situations where something is given for something else (usually money). In the accreditation situation in Iran, meeting the specified standard would have a financial impact and therefore a considerable level of conformity resulted to enable the hospitals to gain the requisite score. But the development of standards was not based on a dialogue as to how to improve performance. Although the quality standards were to encourage continuous improvement in performance, the hospitals did not see them this way. Pomey et al. (2004) suggest that in Canada, the development of standards for continuous improvements, involving more professionals and enabled them to identify their organisational weaknesses, improving communication, but only marginally improving clinical practices. This differs from the Iranian situation where, it seems, the participants do not consider the potential learning from the standards.

In many cases, the hospital participants felt that they do not have the capabilities to comply with the standards and that this had not been considered in the setting of standards.

"It is not based on the hospital's capability. We don't think they evaluate what we have or are capable of doing." (Supervisor: Private Hospital E)

Therefore, there are problems with how the standards have been developed. Transactional steering approaches lead to conformity but a latent resistance to and the non-acceptance of accreditation standards underpins this conformity. Cooper et al. (2014) suggest that accreditations create institutional pressure for change in systems and organisations. Shaw et al. (2010) also suggest that in many countries, hospital systems change in preparation for accreditation. Where the standards are considered irrelevant, the participants may not feel any desire to meet them. Hospitals may attempt to rebut the controls, but being unable to do so, may reoreintate their internal activities as they attempt to conform whilst actually resisting the controls. Further organisational resistance is shown to the accreditation system in response to how the standards are applied.

\subsection{Applying the Standards: Non-Negotiable and "unfair"}

Six months before the accreditation visit, hospitals are given the relevant forms to self-assess their performance against the indicators specified in Table 3 and 4. The completed forms are then handed to the surveyors. The surveying groups typically include two consultants from different disciplines such as internal medicine and paediatrics, two paramedics including one radiologist and one laboratory technician, one nurse, one medical equipment engineer, one establishment and construction expert, one administrative and personnel expert, one financial and budget expert, a team coordinator, healthcare management expert and other experts if required. A representative from insurance organisations is also a permanent member of this surveying group (Moghimi, 2004, p. 8).

The surveyors score the hospitals on the basis of the self-assessed information. The surveyors act as peer reviewers, drawing on the self-assessment forms filled by the hospitals to conduct their review. Some guidelines are provided to assist the surveyors to assign related scores to the activities of the hospitals. Nonetheless, in most cases there are no guidelines, apart from the surveyors' judgement on the basis of their observation and interviewing.

The interviewees suggested that the manner in which the accreditation is conducted to apply the standards may be considered somewhat simplistic and non-negotiable, tending to depend mainly on the 
subjective view of the surveyors. For instance, the surveyors check the list of equipment and award scores, but they do not assess whether the equipment is used or not.

"The surveyors only check the existence of equipment; they have never checked whether we can use it or..." (Head of Para-clinic Dept.: Public Hospital F)

Different hospitals complained about how their particular circumstances were not taken into account, for example:

"According to our situation and capability as a single-specialty hospital, we are not able to completely fulfil the requirements of the accreditation program ... the standards are set for general hospitals and, therefore, impractical and unrealistic for us. For example, some equipment or services are not necessary in this hospital, but we are still asked to have them due to the compulsory nature of the accreditation' (Manager: Hospital B)

'The evaluation is not based on the hospital's capability. We don't think they evaluate what we have or are capable of doing and offering to patients.' (Supervisor: Hospital E)

The hospitals also suggest that there is a mandatory nature to the accreditation which forces them to comply with surveyors' requests. For example;

"Sometimes they (surveyors) for instance ask for the provision of a new service that is not to the benefit of the hospital, but we must comply with them in any case. It has a few times happened that the surveyors have asked for some documents that we do not think are worth preparing, but it is obligatory and we must draw up, when asked." (Manager: Public Hospital C).

The subjective approaches used in scoring hospitals lead to many concerns, primarily because hospitals do not understand how the scores are derived and, secondly, because they feel different types of hospitals are treated differently.

"The scoring process is not clear for us. It is totally up to the surveyors' judgements what score to give to the hospital. Therefore, we do not know how to perform to get the full score for an activity or process." (Member of quality improvement office: Public Hospital F)

A more relational approach to the application of standards could help hospitals to understand what changes the accreditation system are attempting to achieve, so staff could hold a more constructive view about the accreditation process. Pomey et al. (2004) for example, suggests that positive incentives such as training and accreditation awareness lectures could help accreditations to serve as an agent of change. Tension between private and public hospitals is visible because private hospitals hold the perception that the accreditation programme benefits the public hospitals. As Tables 3 and 4 portray, standards for both public and private hospitals are the same, since the main objective is 'continuous quality improvement' at all levels of hospitals' activities (Moghimi, 2004, p. 5). However, participants from private hospitals also feel aggrieved.

"Surveyors assess this hospital more strictly than the public hospitals. They normally carry a negative view towards private hospitals ... I know that the requirements of the accreditation programme are not properly observed in the public hospitals, as I have worked there. However, they normally get a better grade than us very easily." (Head of A\&E: Private Hospital H)

“... I feel they [surveyors] don't give us a fair score, because I don't think it is fair to compare us with the other advanced public hospitals and evaluate our work by the same checklists of standards." (Manager: Private Hospital E) 
"They compare this hospital with publicly-funded advanced public hospitals, which is not fair in my perception." (Supervisor: Private Hospital E)

Private hospitals also indicate they are always distrustful of the evaluation results, because they do not have a representative in the evaluation team and the evaluation is performed by the surveyors of the universities and the Ministry of Health who belong to the public sector. Nonetheless, the public hospitals also echo their lack of faith in the accreditation system:

"They (the surveyors) do not consider our "out-of-hand" limitations and capabilities in their evaluation." (Manager: Public Hospital B)

Both private and public hospitals seemed to share a distrust of the accreditation scores, albeit that they gave different reasons for this disbelief. Arguably, the similarity in views stems from the underpinning rationalities associated with the accreditation scheme. As Broadbent and Laughlin (2009) suggest with transactional steering,

"Measures come first and either assumes to seek to define the implied values underlying these numbers... 'Ownership' of the performance measurement systems may be difficult to achieve if the required ends do not reflect the taken-for granted organisational values" (Broadbent and Laughlin, 2009, page 287).

In this case the subjective scoring of the hospital performance for both hospitals, whether private or public meant the ownership of the scores and the process was difficult to accept. Despite this, there is one aspect of the accreditation standards that all the hospitals are supportive of, since it is founded on shared interpretive schemes.

\subsection{Accreditation of religious standards and shared religious values}

Iran's ethos is grounded on a multifaceted amalgamation of traditional and Islamic religious values (Hashemi and Postel, 2010). As table 3 demonstrates, the category of the standards related to religious and humane values represents ten per cent of the total range of scores that can be earned. One of the researchers observed a considerable number of spiritual and health care guidelines concerning healing and patients' assistance displayed on the hospitals' notice boards. This procedure corroborates many statements of this nature which are part of the instructions set by the hospitals' evaluation policies set by the Government (e.g. MoH-Ministry of Health 1997a, 1997b). Islamic principles and law regulate and influence all aspects of life and is strictly adhered to. Questioning, ignoring or rejecting those standards is considered highly inappropriate, since they are grounded in shared religious beliefs, which is a key element that underpins the Islamic principles established in Iran. The set of questions composing these standards encompassed values based on compassion and ethics fitting with Islamic values. Therefore, scores are allocated according to the hospitals' capacity to demonstrate that those principles are related to their daily practices, worship, healthcare needs and medical staff's 'ethics'. The sets of questions contained in the standards established for the religious values included inter alia observing the religious values such as being compassionate to patients, paying attention to the ethical and emotional treatment of patients; meeting gender segregation requirements; ensuring that there is a religious centre in the hospital (this centre refers to an administrative body available to handle and manage the religious ceremonies).

Since most of these religious values are not generated by people's consensus, but based on the Islamic principles, they are seemingly not in conflict with people's way of living and are more acceptable to the hospitals' staff, who tend to conform to these particular standards without any challenge. Moreover the religious values, an example of Laughlin's "cultural beliefs and values, (Laughlin, 1991, page 213) are shared by both the accrediting team and the hospital staff. Accordingly, hospital staff suggest that these shared religious beliefs provide the motivation for complying with all the demands of the accreditation programme (Jayasinghe \& Soobaroyen, 2009; Lewis, 2001). 
"...our motive for complying with the accreditation programme is helping patients. We hope that its guidelines help us to do this invaluable task ..." (Sister: Private Hospital E)

"In any situation, we basically observe the religious values." (Manager: Public Hospital D)

This was not surprising since "many Muslims around the world consider their beliefs to be the most important aspect of their spiritual essence, especially as they relate to daily practices, health care needs, medical ethics, and end-of-life treatment choices" (Abu-Ras and Laird, 2011, page 22). Islamic values and beliefs are important interpretive schemes that impact upon how the accreditation processes were understood. They believe their religious values help patients to recover and are keen to take on board any initiative that can assist them in this purpose. Abu-Ras and Laird (2011) suggest "the religious values and beliefs of Muslims are markedly different from those traditionally found in the Western Hemisphere" (Abu-Ras and Laird, 2011, page 48). This was evident in the interviews with hospitals' participants and, thus, the interviewer did not dwell on it, because of its taken for granted nature. Commenting on the Iranian accreditation programme, Izadi et al. (2013) emphasise the importance in Iran of considering Islamic religious values within the accreditation systems, especially when standards derive from secular systems such as the JCI. Higher scores are often received by hospitals that comply with the religious standards and this influences how the whole regulatory programme is perceived. For example, Kamla et al. (2006) explains argue that in Islam the belief is that "more generally, life, prosperity, well-being and wealth are to be safeguarded and enhanced through mercy and justice" (Kamla et al., 2006, page 252). These sentiments suggest that, although the accreditation seemed to be transactional in approach, the strong shared religious values ensured conformity. This was the case despite the fact that different "measures of quality, relevance or excellence" seem to flow from the societal steering media (Broadbent et al., 2010).

\subsection{Periodic Site Review and Accreditation Outcomes}

The hospital accreditation visit is conducted annually beginning with a pre-arranged site visit by a team of surveyors. The visit usually lasts one week depending on the size of the hospitals and the number of in-patient beds. The site review is undertaken into two stages. The first review visit is to the accident and emergency (hereafter A\&E) department, and is conducted independently of the remainder of the hospital. The second visit is the whole hospital assessment and it only takes place if the A\&E obtains acceptable scores. This means that there is considerable pressure on both managers and clinicians to meet the standards for A\&E. There are tensions between the managers and the clinical staff, which becomes evident during the preparations for the periodic site reviews element of the accreditation.

Managers complain about the attitude of the clinicians. Many clinicians remained disengaged from the process, despite attempts by the hospital managers to find ways to encourage them to comply with the requirements of the accreditation programme.

"Surveyors frequently refer to some problems related to the activities of our consultants (e.g. their low rate of attendance in the hospitals committee and meetings). But, this is not under our control." (Manager: Public Hospital B)

"We have problems with the clinicians who don't comply with the requirements of the accreditation programme (e.g. filling the patients' record completely). We try to encourage them to do so, because we lose points if it is not done properly. I try to do this through senior managers [director] of this hospital." (Sister: Private Hospital E)

Interviews with physicians indicate that they are either unaware of the accreditation programme or see it more as a formal activity that required compliance rather than a quality improvement mechanism.

"I know there is an evaluation programme, but I am not aware what it does and what its standards are." (Consultant: Public Hospital F) 
In fact some clinicians suggested that the accreditation scheme does not have an impact on their work.

"I don't suppose the accreditation programme limits my freedom and independence, because it is only an annual checking system which stays just for a few days with us in the hospital." (Head of ED: Private Hospital E)

Seemingly, then, the accreditation scheme is neither intrusive nor freedom-reducing (at least for the clinicians) as is typical of transactional regulatory processes. Other studies on accreditations have shown that it is the nurse managers who take leadership roles in preparing for accreditation visits. It is in this respect that our findings are similar to these studies (Duckett, 1983; Pomey et al., 2004). Both the private and the public hospitals demonstrated the two aspects, professional (held by the clinicians) and managerial (held by the managers), often associated with healthcare organisations (Abernethy and Chua. 1996; Kurumanki, 2004; Modell, 2001, Lehtonen, 2007). Nonetheless, whilst other studies show that accreditation preparations lead to "sharing of information and greater service integration" (Pomey, et al., 2004, page 122), here there is a sense that clinicians are very powerful and they can choose not to engage. Most of the interviewees indicated that the quality improvement activities involving consultants do not progress properly, because they are reluctant to participate in and cooperate with such activities. Their tight schedules also seem to impact on their indifference toward the accreditation programme.

"...consultants tend to not attend the time requirements of the hospitals, because of the power they hold." (Third-party surveyor)

Supposedly, if the underpinning ethos of the accreditation scheme is relational, all stakeholders would have a shared concern for ways of improving processes and practices and this would emanate through the whole preparation for the visit. Transactional approaches are more attentive to outputs, the ends rather than the means.

Where A\&E departments do not achieve a satisfactory score (i.e. falling into the non-compliant category - grade 4; between 10869 - 13218, Table 5), the hospitals are given three months at most to rectify the problems and prepare for a re-evaluation of its A\&E department. This scheme may induce hospitals to neglect their main activities to obtain higher grades for their A\&E accreditation and then be able to move to the second phase of the process.

During the second phase the surveyors investigate different aspects of the hospital activities, looking at medical equipment and clinical and paramedical spaces in an attempt to evaluate the hospitals holistically. They interview medical staff (mainly nurses) and sometimes patients, and finally they review the related documents.

At the end of the accreditation visit, the surveyors are expected to hold a meeting with hospital managers to brief them on existing non-compliances against the standards. However, this briefing meeting still does not change the fact that hospital staff still do not understand how the scores the hospitals receive are derived. The final written report of the review is usually sent to the hospitals within a month of the site visit. Nonetheless, no suggestions on how to improve the scores are provided. Table 5 displays the range of scores and corresponding grades granted to the hospitals. The grade is used as a threshold for hospitals' eligibility to raise their tariffs for hotel-type services (MoH- Ministry of Health, 1997a).

Table 5. The scoring system of the accreditation programme for hospitals

Source: Moghimi (2004, p. 12)

During interviews both private hospital managers and accreditation surveyors emphasised the importance of the high tariff to private hospitals especially. 
"Our motive to complying with this accreditation programme is to get high tariffs; because without them it is difficult for us to survive. In fact, they are our main financial source." (Manager: Hospital $\mathrm{C}$, private hospital)

"The main reason for [private] hospitals complying with the accreditation programme is to get high tariffs, since most of them are suffering from low income." (Third-party surveyor)

In the case of the private hospitals the accreditation scores can visibly have a significant impact on their activities. The public hospitals, on the other hand, are not as dependent financially on the results of the accreditation, since they do have significant income from the public finances.

There are few differences in the attitude of private and public hospitals and, therefore, the standards employed in the accreditation process are the same for both. All hospital staff suggested that they would prefer departmental financial incentives to be associated with a higher grade.

"There are no formal financial incentives for the departments that get higher score. They might get some rewarding leave or overtime hours which are very limited." (Head of quality improvement office: Hospital D-Public).

The lack of a clear reward at the individual and departmental level could remove the incentives for making efforts to achieve a better grade and performance (Custers et al., 2007). Although the financial impacts were gained through the services that the hospitals could provide, these impacts were not felt at the departmental or individual levels. Where a hospital is considered as non-compliant, namely achieving a grade four, it is given three months to improve its deficiencies and to solve the problems identified during the evaluation process. A final decision is made after a second visit to substandard hospitals. Hospitals considered 'substandard (Non-compliant)', after a second visit, are prevented from providing some services to patients and those classified as 'unauthorised' can only work as a limitedsurgery clinic, rather than as a hospital. This further attests to the transactional nature of the scheme, explaining again why hospitals conformed to the regulatory control.

In summary, the accreditation system as applied in Iran, although aimed at continuous improvement in quality of healthcare delivery, rather relies on many input standards. The accreditation scores of hospitals depend on subjective assessments made by survey teams. The outcome from the accreditations has some financial impacts at the organisational level, and thus the control system seemingly is transactional in its steering approach. Whilst the hospitals showed some resistance to the process, they do comply with its requirement, suggesting some amount of reorientation of organisational activities. The shared cultural interpretative schemes of religious values tend to make the accreditation seem more acceptable than it might have done. The next section discusses these organisational responses to accreditation system and concludes our study.

\section{Discussion and final considerations}

We argue in this paper that an accreditation programme is an example of a regulatory control system attempting to change hospital activities through the standards against which they are assessed. Understanding organisational participants' perceptions of these standards, the accreditation process and the outcomes are important for assessing the effectiveness of accreditation systems and whether they can lead to organisational change. We analyse the perceptions of the hospitals' participants in Iran to the Iranian National Accreditation of Hospitals Programme. Our findings show that, whilst there is some amount of resistance to the scheme, hospitals tend to conform to its requirements; in some cases even fabricating evidence in their bid to and demonstrate compliance. The key factors explaining conformity include the compulsory nature of the process, the financial impetus and the shared religious values. In effect the transactional nature of the process and the outcomes associated with the accreditation enable 
conformity. Resistance, on the other hand, is driven by the perceived inappropriateness of the standards. The resistance remains covert rather than overt. These reactions together (i.e. conformity and resistance) are suggestive of a reorientation response (Broadbent and Laughlin, 2013; Laughlin, 1991).

Broadbent and Laughlin (2013) suggest that reorientation strategies, where there is resistance to regulatory controls, take place through absorption practices or through boundary management. With absorption, the organisation manages "unwanted intrusions" by soaking them up through the activities of specialist working groups thereby protecting the core activities (Broadbent and Laughlin, 2013, page 213). With reorientation by boundary management, senior managers act as a conduit for the external regulators, whilst protecting the interpretive schemes of the organisation. In both cases there are organisational changes, but the core organisational values are protected from the intrusion.

In this particular case of accreditation of hospitals in Iran, the responses made to the accreditation processes were attempts by organisations to conceal their inability to meet the standards. There is no evidence of boundary management, nor evidence of absorption. Reorientation took place in the form of some amount of gaming.

This form of reorientation takes place because the nature of the standards set to grade hospitals activities are perceived as unrealistic, as previous citations indicate. The perception is that the accreditation standards do not highlight the strengths of the hospitals nor do they reveal their weaknesses and mistakes. Hospitals simply receive a list of grades related to their main activities, but they still do not get explanations and/or suggestions on how to improve them. There is the suggestion that some of the accreditation's requirements exceed hospitals' capacities and facilities and, therefore, they are assessed on aspects over which they have no control (e.g. human resources). This situation led to a sense of indifference, lack of ownership and sometimes indignation.

Shaw (2000) suggests that standards should be developed or adapted to reflect national legislation, economics, culture and demand, rather than being replicated globally, as it is the case of Iran. Where the standards have been adjusted to reflect the context, such as the inclusion of religious standards, the accreditation was deemed acceptable, otherwise they are resisted. In this case the resistance was hidden because of the compulsory nature of the system. Pomey et al. (2004) argue that the institutional pressures created by compulsory accreditations need to be backed by incentives to encourage organisations to engage meaningfully in the process, through learning and training. In effect, the processes of accreditation (standards development, application of standards, self-assessment etc.) can be used to encourage organisational change. We do not see this happening in this case study. Cooper et al. (2014) also signal the important role powerful interests (in their case, academic Deans) can play in championing issues within the standards to instigate change. Rather, what we see in Iran is the perception that the standards are inappropriate.

As Broadbent and Laughlin (2013) argue, in transactional approaches to control, the measures come first and are developed on assumed values. A more relational and discursive approach could create an opportunity for hospitals to reflect on and improve their own performance. Their knowledge could be incorporated in the definition of standards. Where more relational mechanisms are used to regulate and there is more discussion of the causes and effects of actions between organisations and their regulators (Broadbent et al., 2010), they develop a shared understanding of issues pertaining to hospitals. Quality of care may require standardisation but it should not discourage autonomy and creativity.

Whilst the Iranian case shows latent resistance, there is a significant level of conformity to the accreditation programme. Hospitals conformed to the accreditation for three reasons, the possible financial benefits associated (especially in the case of private hospitals) with it at the organisational level, its compulsory nature, and the shared religious values that all parties held.

Firstly, the accreditation programme in Iran is premised on the transactional approach of "something for something", for the financial transfers the organisations receive there is a need for performance 
accountability by meeting the accreditation standards. However, the financial impacts of accreditation performance were seen differently by the private and the public hospitals. The financial consequences for the public hospitals were seen by the private hospitals as negligible, since the public sector hospitals in Iran are funded by the Government and, therefore, have a stable source of funding. There seemed to be no apparent financial penalty for the public hospital in the event of them not achieving the desired standards of the accreditation system. However, these public hospitals theoretically could be demoted to clinics and the type of service provided by them altered. In this respect, it seems the accreditation system as operated in Iran is similar to other public management performance measurement systems .Whilst accreditations are often differentiated by their "non -punitive nature" (Montague,2003), in this case study there seems to be elements of punishment associated with the system. The public sector hospitals were compelled to conform.

The situation was different for the private hospitals that faced constant and continuing financial difficulties. It was therefore imperative for them to achieve a high score, which impacted on the tariff they set for their services. The fabrication of pre-evaluation documents was an attempt to meet the demands of the A\&E standards (table 4) in order to gain the financial resources. The fact that they are prepared to go to this extent shows the significance of money as a steering mechanism (Broadbent and Laughlin, 2009, page 292). It also demonstrates the problems that transactional regulatory processes may face when there is not a market to set prices to deal with the transfers of money. The expectations of the regulators (in this case the desire for improved quality of health care) stand the risk of not being achieved where the financial flows are necessary but not considered sufficient enough to drive the organisational changes necessary to meet the standards.

All the hospitals participated in the accreditation programme, because it is legally required. The mandatory nature of the programme means hospitals cannot opt out: the accreditation has legal support. The accreditation is a mode of governance that can exert disciplinary power over the hospitals by preventing them from providing services. Therefore, there is conformity because of the fear the hospitals have of being closed down if they do not reach the required standard. The state has enormous power and could wield this on hospitals.

A close look at the case seems to suggest that the hospitals' interviewees are also prepared to conform to the accreditation requirements, because of shared religious values. The Islamic values are very strong interpretive schemes that are taken for granted and that underpin all aspects of life in Iran. The inclusion of religious standards within the accreditation has been heralded and was intentionally included to ensure the acceptability of the process to believers (Izadi et al., 2013). Thus, even if the accreditation programme is seemingly transactional, it is taken as a relational process, although it is not based upon deliberation and negotiation. In discussing relational steering, Broadbent et al. (2010) do not develop the bases on which relational steering may be founded. Nevertheless, they point to the complexities associated with actual practices. For example, in their study of Higher Education in the UK, they argue that many of the regulatory controls pass through intermediate organisations that can reshape the transactional controls, making the processes more relational. This study suggests that, whilst the accreditation standards reflect transactional definition of standards, or the ends required, the means or processes of working towards these standards may be underpinned by shared religious values. In effect, transactional steering need not be undertaken in a "command and control" manner.

Our argument is that the responses of the hospitals reflected reorientation rather than colonisation. Reorientation recognises that the regulatory controls must be managed to enable the organisational activities to continue without change to the organisational interpretive schemes. Broadbent and Laughlin (2013) argue that colonisation involves forced changes in the interpretive schemes of organisations. There is a fundamental shift in the "genetic code" of the organisations being controlled such that they take on the values contained in the regulatory controls. We did not see this taking place in the accreditation programme as it operates in Iran; the hospitals continued to focus on their key mission of improving the health of the Iranian people. 
To conclude our specific case, we have argued that the hospital accreditation programme of Iran is a regulatory control system that shows signs of transactional steering. However, in the context of Iran, and the shared underpinning religious beliefs in which the programme is implemented, the dichotomy of transactional and relational steering may not be as sharply divided as may be the case in other settings. In Iran, the elements of accreditation associated with Islamic values are taken for granted and are "amenable to substantive justification" and, therefore, regulative because they regulate established behaviour and are not considered to be reducing the freedom by which the organisations act (Laughlin and Broadbent, 1993, page 341). Nevertheless, other aspects of the accreditation are less well accepted; but they are still accomplished, due to the material financial recompense that they entail - i.e. "something for something' associated with transactional steering. This recognition reasserts the importance of studying control systems in the context in which they operate.

On a more general policy level, our study has shown that accreditations as control systems offer the accreditor an opportunity to impact on how activities are undertaken. Nonetheless, as with other systems of control, the goals of the control system need to be agreed and shared by all stakeholders who will have a part to play in achieving the objectives. Healthcare organisations need to work with the accreditor (the government, in this case) on all the three stages - i.e. developing and applying standards and the periodic review to enable an effective accreditation programme to impact on the quality of healthcare.

\section{References}

Abernethy, M. A., Chua,W.F. and Grafton, J. \& Mahama, H. (2007). Accounting and Control in Health Care: Behavioural, Organisational, Sociological and Critical Perspectives. In: Chapman, C. S., Hopwood, A. G. \& Shields, M., D. (eds.) Handbook of Management Accounting Research. Oxford: Elsevier.

Abernethy, M. A. and Chua,W.F. (1996). A Field Study of Control System "Redesign": The Impact of Institutional Processes on Strategic Choice. Contemporary Accounting Research, 13(2), 569-606.

Abu-Ras, W. and Laird, L. (2011). How Muslim and non-Muslim chaplains serve Muslim patients? Does the interfaith chaplaincy model have room for Muslims' experiences? Journal of Religion and Health, 50(1), 46-61.

Al Tehewy, M., Salem, B., Habil, I. and El Okda, S. (2009). Evaluation of accreditation program in non-governmental organizations' health units in Egypt: short-term outcomes. International Journal for Quality in Health Care, 21(3), 183-189

Agrizzi, D. (2008). Assessing English hospitals: contradiction and conflict. Journal of Accounting \& Organizational Change, 4, 222-242.

Agyemang, G. and Broadbent, J. (2015). Management Control Systems and the management of research in universities. Accounting, Auditing \& Accountability Journal, 28 (7), 1018-1046.

Arce, H. E. (1999). Report. Accreditation: the Argentine experience in the Latin American region. International Journal for Quality in Health Care, 11, 425-428.

Bahadori, M., Ravangard, R. and Alimohammadza, K. (2015). The Accreditation of Hospitals in Iran. Iranian Journal of Public Health, 44(2), 295-296.

Bartunek, J. (1984). Changing interpretive schemes and organisational restructuring: the example of a religious order. Administrative Science Quarterly, 29, 355-372.

Beaulieu, N. D. \& Epstein, A. M. (2002). National Committee on Quality Assurance health-plan accreditation: predictors, correlates of performance, and market impact. Medical Care, 40, 325-37.

Beckford, J. A. and Richardson, J. T. (2007). Religion and regulation. The SAGE Handbook of the Sociology of Religion, London: Sage, 396-418.

Bevan, G. \& Hood, C. (2006b). What's measured is what matters: targets and gaming in the English public health care system. Public Administration, 84, 517-538.

Boehle, J. (2010). Religious NGOs at the UN and the Millennium Development Goals: an introduction. Global Change, Peace \& Security, 22(3), 275-296.

Braithwaite, J., Greenfield, D., Westbrook, J., Pawsey, M., Westbrook, M., Gibberd, R., Naylor, J., Nathan, S., Robinson, M. \& Runciman, B. (2010). Health service accreditation as a predictor of 
clinical and organisational performance: a blinded, random, stratified study. Quality and Safety in Health Care, 19, 14-21.

Braithwaite, J., Westbrook, J., Johnston, B., Clark, S., Brandon, M., Banks, M., Hughes, C., Greenfield, D., Pawsey, M. \& Corbett, A. (2011). Strengthening Organizational Performance through Accreditation Research-a Framework for Twelve Interrelated Studies: The Accredit Project Study Protocol. BMC research notes, 4, 390.

Braithwaite, J., Shaw, C.D., Maldovan, M., Greenfield, D., Hinchcliff, R., Mumford, V., Kristencen, M.B., Westbrook, J., Nicklin, W., Fortune, T., Whittaker, S. (2012). Comparison of health service accreditation programs in low- and middle-income countries with those in higher income countries: a cross-sectional study. International Journal for Quality in Health Care, 24(6), 568-577.

Broadbent, J., Jacobs, K. \& Laughlin, R. (2001). Organisational resistance strategies to unwanted accounting and finance changes. Accounting, Auditing \& Accountability Journal, 14, 565-586.

Broadbent, J. \& Laughlin, R. (2009). Performance management systems: A conceptual model. Management Accounting Research, 20, 283-295.

Broadbent J, Laughlin R. and Gallop C. (2010). Analysing Societal Regulatory Systems with Specific Reference to Higher Education in England. Accounting, Auditing and Accountability Journal. 23(4), 506-531.

Broadbent, J. and Laughlin, R. (2013). Accounting Control and Controlling Accounting: Interdisciplinary and Critical Perspectives. Emerald Group Publishing.

Brown, M. G. (1996). Keeping Score: Using the Right Metrics to Drive World-Class Performance. New York. Quality Resources.

Cerqueira, M. (2006). A Literature Review on the Benefits, Challenges and Trends in Accreditation as a Quality Assurance System. Victoria: British Columbia Ministry of Children and Family Development.

Chang, L. (2007). The NHS performance assessment framework as a balanced scorecard approach; limitations and implications. International Journal of Public Sector Management, 20(2), 101-117.

Chenhall, R. H., Hall, M. \& Smith, D. (2010). Social Capital and Management Control Systems: A Study of a Non-Government Organization. Accounting, Organizations and Society, 35, 737-756.

Conrad, L. and Uslu, P.G. (2012). UK health sector performance management: Conflict, crisis and unintended consequences. Accounting Forum, 36, 231-250.

Cooper, S., Parkes, C. and Blewitt, J. (2014). Can accreditation help a leopard change its spots?

Accounting, Auditing \& Accountability Journal, 27(2), 234-258.

Cret, B. (2011). Accreditations as local management tools. Higher Education, 61(4), 415-429.

Custers, T., Klazinga, N. \& Brown, A. (2007). Increasing performance of health care services within economic constraints: working towards improved incentive structures. Zeitschrift für ärztliche Fortbildung und Qualität im Gesundheitswesen, 101, 381-388.

De Bruijn, H. (2002). Performance measurement in the public sector: strategies to cope with the risks of performance measurement. International Journal of Public Sector Management, 15, 578-594.

De Walcque, C., Seuntjens, B.,Vermeyen, K., Peeters, G. \& Vinck, I. (2008). Comparative study of hospital accreditation programs in Europe. Health Services Research (HSR). KCE reports. Brussels: Belgian Health Care Knowledge Centre (KCE).

Duckett, S. (1983). Changing Hospitals: The Role of Hospital Accreditation. Social Science \& Medicine. 17, 1573-1579.

Eaton, J. S. (2006). An Overview of Us Accreditation, Council for Higher Education Accreditation. Washington.

Farzianpour, F., Askari, R., Hamedani, A. T., Khorshidi, G., Amirifar, S. and Hosseini, S. (2011). Accreditation of emergency department at a teaching hospital in Tehran University of Medical Sciences in 2010, American Journal of Economics and Business Administration, 3(3), 498-505.

Fried, A. (2010). Performance measurement systems and their relation to strategic learning: A case study in a software-developing organization. Critical Perspectives on Accounting, 21, 118-133. 
Gifford, D. R. \& Garcieri, D. L. (2007). Hospital Information for the Public: How does the accreditation process work? [Online]. Available at: http://www.health.ri.gov/hsr/facilities/hospitals/process.php

Giraud, A. (2001). Accreditation and the quality movement in France. Quality and Safety in Health Care, 10(2), 111-116.

Greco, M., Sweeney, K., Brownlea, A. \& McGovern, J. (2001). The practice accreditation and improvement survey (PAIS). What patients think? Australian Family Physician, 30, 1096-100.

Greenfield, D. \& Braithwaite, J. (2008). Health sector accreditation research: a systematic review. International Journal for Quality in Health Care, 20, 172-183.

Hinchcliff, R., Greenfield, D., Moldovan, M., Westbrook, J. I., Pawsey, M., Mumford, V. and Braithwaite, J. (2012). Narrative synthesis of health service accreditation literature. British Medical Journal quality \& safety, bmjqs-2012-000852.

Haigh, M. \& De Graaf, F. (2009). The implications of reform-oriented investment for regulation and governance. Critical Perspectives on Accounting, 20, 399-417.

Halverson, P. K., Nicola, R. M. \& Baker, E. L. (1998). Performance Measurement and Accreditation of Public Health Organizations: A Call to Action. Journal of Public Health Management and Practice, 4, 5-7.

Hashemi, N. and Postel, D. (2010). The People reloaded - the green movement and the struggle for Iran's future. Melville House Publishing, New York.

Heuer, A. J. (2004). Hospital accreditation and patient satisfaction: testing the relationship. Journal for Healthcare Quality, 26, 46-51.

Hood, C. (1991). A public management for all seasons? Public Administration, 69(1), 3-19.

Hood, C. (1995). The 'New Public Management' in 1980's: Variation on a Theme'. Accounting, Organisations and Society, 20, 93-109.

Hood, C. (2007). Public service management by numbers: Why does it vary? Where has it come from? What are the gaps and the puzzles? Public Money and Management, 27(2), 95-102.

Hopper, T.; Tsamenyi, M.; Uddin, S. and Wickramasinghe, S. (2008). Management accounting in less develop countries: what is known and needs knowing. Accounting, Auditing \& Accountability Journal, 22(3), 469-514.

Hoque, Z. (2014). 20 years of studies on the balanced scorecard: Trends, accomplishments, gaps and opportunities for future research. The British Accounting Review, 46, 33-59.

Huang, P., Hsu, Y. H. E., Kai-yuan, T. \& Hsueh, Y. S. (2000). Can European external peer review techniques be introduced and adopted into Taiwan's hospital accreditation System? International Journal for Quality in Health Care, 12, 251-254.

Ingvarson, L., Elliott, A., Kleinhenz, E. and McKenzie, P. (2006). Teacher education accreditation: A review of national and international trends and practices. Teacher Education, pp. 1.

Ito, H., Iwasaki, S., Nakano, Y., Imanaka, Y., Kawakita, H. \& Gunji, A. (1998). Direction of quality improvement activities of health care organizations in Japan. International Journal for Quality in Health Care, 10, 361-3.

Izadi, M., Hoseinpourfard, M., Ayoubian, A., Karbasi, M., Jahangiri, M. and Jalali, A. (2013). A Survey to the Implementation of Islamic Standards in the Hospitals of Iran for Attraction of Muslim Medical Tourists. International Journal of Travel Medicine and Global Health, 1(3).

Jacobs, K. (2001). Alternative methods to examine hospital efficiency: data envelopment analysis and stochastic frontier analysis. Health Care Management Science, 4, 103-115.

Jayasinghe, K. \& Soobaroyen, T. (2009). Religious "spirit" and peoples' perceptions of accountability in Hindu and Buddhist religious organizations. Accounting, Auditing \& Accountability Journal, 22, 997-1028.

Kamla, R., Gallhofer, S. and Haslam, J. (2006). Islam, nature and accounting: Islamic principles and the notion of accounting for the environment. Accounting Forum, 245-265.

Kerssens-van Drongelen, I. (2001). The iterative theory-building process: rationale, principles and evaluation. Management Decision, 39(7), 503-512. 
Kurunmaki, L. (2004). A hybrid profession - the acquisition of management accounting expertise by medical professionals. Accounting, Organizations and Society, 29, 327-347.

Laughlin, R. (1991). Environmental Disturbances and Organizational Transitions and Transformations: Some Alternative Models. Organization Studies, 12(2), 209-232.

Laughlin, R. (1995). Methodological themes; Empirical research in accounting: alternative approaches and a case for "middle-range" thinking. Accounting, Auditing \& Accountability Journal, 8, 63-87.

Laughlin, R. (2004). Putting the Record Straight: A Critique of 'Methodology Choices and the Construction of Facts: Some Implications from the Sociology of Knowledge'. Critical Perspectives on Accounting, 15, 261-277.

Lewis, M. K. (2001). Islam and Accounting. Accounting Forum. Wiley Online Library, 103-127.

Lehtonen, T. (2007). DRG-based prospective pricing and case-mix accounting-Exploring the mechanisms of successful implementation. Manag ment Accounting Research. 18, 367-395.

Loeb, J. M. (2004). The current state of performance e measurement in health care. International Journal for Quality in Health Care, 16, 15-19.

Mack, N., Woodsong, C., Macqueen, K. M. \& Namey, E. (2005). Qualitative Research Methods: A data collector's field guide. North Carolina, Family Health International (FHI).

Majlis (1985). The act of the Islamic Republic of Iran's parliament (Majlis) on the establishment of Ministry of Health and Medical Education. Tehran: Islamic parliament of Iran.

Majlis (1987). The act of the Islamic Republic of Iran's parliament (Majlis) on the establishment of Ministry of Health and Medical Education: Practical instruction for Article 8. Tehran: Islamic parliament of Iran.

Majlis, (1988a). The act of the organisation and duties of Ministry of Health and Medical Education (Majlis): Article 1. Tehran: Islamic parliament of Iran.

Mannion, R., Davies, H. \& Marshall, M. (2005). Impact of star performance ratings in English acute hospital trusts. Journal of Health Services Research Policy, 10, 18-24.

Mcintyre, D., Rogers, L. \& Heier, E. (2001). Overview, history, and objectives of performance measurement. Health Care Financing Review, 22, 7-22.

Mellahi, K. \& Wilkinson, A. (2004). Organizational failure: a critique of recent research and a proposed integrative framework. International Journal of Management Reviews, 5(6), 21-41.

Modell, S. (2001). Performance measurement and institutional processes: a study of managerial responses to public sector reform. Management Accounting Research, 12, 437-464.

Modell, S. (2015). Making institutional accounting research critical: dead end or new beginning? Accounting, Auditing \& Accountability Journal, 28(5), 773-808.

Moghimi, A. (2004). Familiarity with evaluation concepts and establishing quality measures. Tehran, Iran: Ministry of Health; Centre for accreditation and supervision; Healthcare organisations evaluation group.

MoH - Ministry of Health and Education (1997a \& b). The instruction of standards and principles of evaluation of the general hospitals. Tehran, Iran: Islamic parliament of Iran, Centre for healthcare accreditation and supervision; Healthcare organisations evaluation group.

$\mathrm{MoH}$ - Ministry of Health and Education (2004). Practical instruction for the quality evaluation of hospitals. Tehran, Iran: Tehran: Islamic parliament of Iran, Centre for healthcare accreditation and supervision; Healthcare organisations evaluation group.

Mohit, A. (2000). Lessons Learned in the Eastern Mediterranean Region from Integration of Mental Health within primary health care in I.R.I. (Islamic Republic of Iran) in: WHO (ed.).

Montague, D. (2003). Accreditation and other external quality assessment systems for healthcare: Review of experience and lessons learned. London: UK Department for International Development, Health Systems Resource Centre.

Neely, A., Adams, C. \& Crowe, P. (2001). The performance prism in practice measuring excellence. The Journal of Business Performance Management, 5, 6-12.

Pomey, M., Contandriopoulos, A., Francois, P. \& Bertrand, D. (2004). Accreditation: a tool for organizational change in hospitals? International Journal of Health Care Quality Assurance, 17, 113124. 
Pomey, M., Lemieux-Charles, L., Champagne, F., Angus, D., Shabah, A. \& Contandriopoulos, A. (2010). Does accreditation stimulate change? A study of the impact of the accreditation process on Canadian healthcare organizations. Implementation Science, 5(31), 1-14.

Pope, C. \& Mays, N. (eds.) (2006). Qualitative research in health care, $3^{\text {rd }}$ ed., Oxford: Blackwell Publishing.

Richardson, S., Cullen, J. \& Richardson, B. (1996). The story of a schizoid organization How accounting and the accountant are implicated in its creation. Accounting, Auditing \& Accountability Journal, 9, 8-30.

Ritchie, J. \& Lewis, J. (eds.) (2003). Qualitative research practice: A guide for social science students and researchers. London: SAGE.

Sadaghiani, E. (1997). Evaluation of Healthcare and Hospital Standards, Tehran, Science \& Art. Moeen Publication.

Sadaghiani, E. \& Zare, H. (2005). The study of accreditation and evaluation system of healthcare organizations. In: Management \& Planning Organization. Tehran: Healthcare Insurance Organization

Scrivens, E. (1995a). Accreditation: protecting the professional or the consumer? Buckingham, Open University Press.

Scrivens, E. \& Lodge, J. (1997). Accreditation: protecting the professional or the consumer? Journal of Management Studies, 34, 167-169.

Scrivens, E. (1997a). Assessing the value of accreditation systems. European Journal of Public Health, 7, 4-8.

Shaw, C. D. \& Brooks, T. E. (1991). Health service accreditation in the UK. International Journal for Quality in Health Care, 3, 133-140.

Shaw, C. D. (2000). External quality mechanisms for health care: summary of the ExPeRT project on visitatie, accreditation, EFQM and ISO assessment in European Union countries. International Journal for Quality in Health Care, 12, 169-175.

Shaw, C. D. (2004b). The external assessment of health services. World Hospitals and Health Services, 40, 24-7.

Shaw, C. D. (2004c). Toolkit for accreditation programs: Some issues in the design and redesign of external health care assessment and improvement systems. Melbourne, Australia: International Society for Quality in Health Care.

Shaw, C. D., Kutryba, B., Braithwaite, J., Bedlicki, M. \& Warunek, A. (2010). Sustainable healthcare accreditation: messages from Europe in 2009. International Journal for Quality in Health Care, 22, 341-350.

Stensaker, B. \& Harvey, L. (2006). Old Wine in New Bottles? A Comparison of Public and Private Accreditation Schemes in Higher Education. Higher Education Policy, 19, 65-85.

Touati, N. \& Pomey, M. (2009). Accreditation at a crossroads: Are we on the right track? Health Policy, 90, 156-165.

Urgel, J. (2007). EQUIS accreditation: value and benefits for international business schools, Journal of Management Development, 26(1), 73-83.

Van Aken, J. E. (2005), Management research as a design science: Articulating the research products of mode 2 knowledge production in management. British Journal of Management, 16(1), 19-36.

Whittaker, S., Burns, D., Doyle, V. \& Fenney, L. P. (1998). Introducing quality assurance to health service delivery - some approaches from South Africa, Ghana and Kenya. International Journal for Quality in Health Care, 10, 263-7.

WHO (2003). World Health Organisation Report.

Yin, R. (2008). Case study research: Design and methods, $4^{\text {rd }}$ ed., London, SAGE.

Zammuto, R.F. (2008). Accreditation and the Globalization of Business. Academy of Management Learning \& Education, 7(2), 256-268.

Zende, V. (2006). Dynamics of accreditation of private hospitals. Express Healthcare Management, November, Mumbai. 
